\title{
Modelling and Simulation of Static Excitation System in Synchronous Machine Operation and Investigation of Shaft Voltage
}

\author{
Arun Kumar Datta, ${ }^{1}$ Manisha Dubey, ${ }^{2}$ and Shailendra Jain ${ }^{2}$ \\ ${ }^{1}$ Central Power Research Institute, Bhopal 462023, India \\ ${ }^{2}$ Maulana Azad National Intitute of Technology, Bhopal 462051, India \\ Correspondence should be addressed to Arun Kumar Datta; akdbpl@gmail.com
}

Received 3 April 2014; Accepted 9 June 2014; Published 3 July 2014

Academic Editor: Ergina Kavallieratou

Copyright (C) 2014 Arun Kumar Datta et al. This is an open access article distributed under the Creative Commons Attribution License, which permits unrestricted use, distribution, and reproduction in any medium, provided the original work is properly cited.

Static excitation system (SES) has been implemented in a specially designed synchronous machine installed in a testing laboratory. This is a large capacity single machine operated in dual mode (i.e., motor or generator) with the help of static sources. It is well known that bearings of the rotating machines are vulnerable to the effects of the shaft voltages caused by the static sources. Shaft voltage is the prime concern for this special machine too due to SES. To find out the exact cause of the shaft voltage, SES of this machine has been modelled with Power Systems software. Various waveforms drawn from the model are validated through computer simulations and actual laboratory tests. Sources of shaft voltages are also analysed thereafter with the FFT analysis of the rotor voltage and current waveforms.

\section{Introduction}

There are various means of supplying dc power to the field winding of an electric machine, for example, dc generator, rotating exciter, and static converter. After the invention of semiconductor devices, static converter has become popular. It is also known as static excitation system (SES). SES came into existence in the beginning of the sixties. Till then the alternators were getting dc field power in the rotor from a $\mathrm{dc}$ generator, separately or coupled with the same alternator shaft. SES was experimented successfully on a steam turbine alternator in the year 1962 [1]. Later on it was implemented not only on the new alternators but also on the existing machines. Due to ease in retrofitting, the old rotating exciters were also replaced with the SES. Starting with steam power generator the SES was extended up to the captive power plant in paper and pulp industries, pump storage power plant, electric locomotive, and gas power plant [2-6]. SES has also been implemented in high power short circuit alternator [7].

Short circuit alternator is basically a synchronous generator in a high power test laboratory which supplies high value of short circuit currents during test on electrical power equipment. A strong dc field is essential to establish and maintain the alternator terminal voltage during the short circuit test. Old testing laboratories were equipped with a separately excited high power dc generator run by an induction motor. A permanent magnet dc generator feeds the field of high power dc generator. In cascading mode a high power $\mathrm{dc}$ is produced which is fed into alternator rotor through slip rings and brushes. Viewing the benefits of SES, short circuit alternators are also started equipped with high power thyristors and fast acting microprocessor controller. One such 1500 MVA short circuit alternator with SES is taken for study in this paper (see Figure 1). Other than SES one more static source that is static frequency converter is connected with the stator terminal of this alternator. With these two static sources the alternator can also be run as a motor [8]. In the beginning machine starts and runs as a motor. During short circuit test the same machine is converted to alternator to deliver the power to the equipment under test.

While rotation, shaft of a high speed large machine is normally charged with certain amount of voltage with respect 


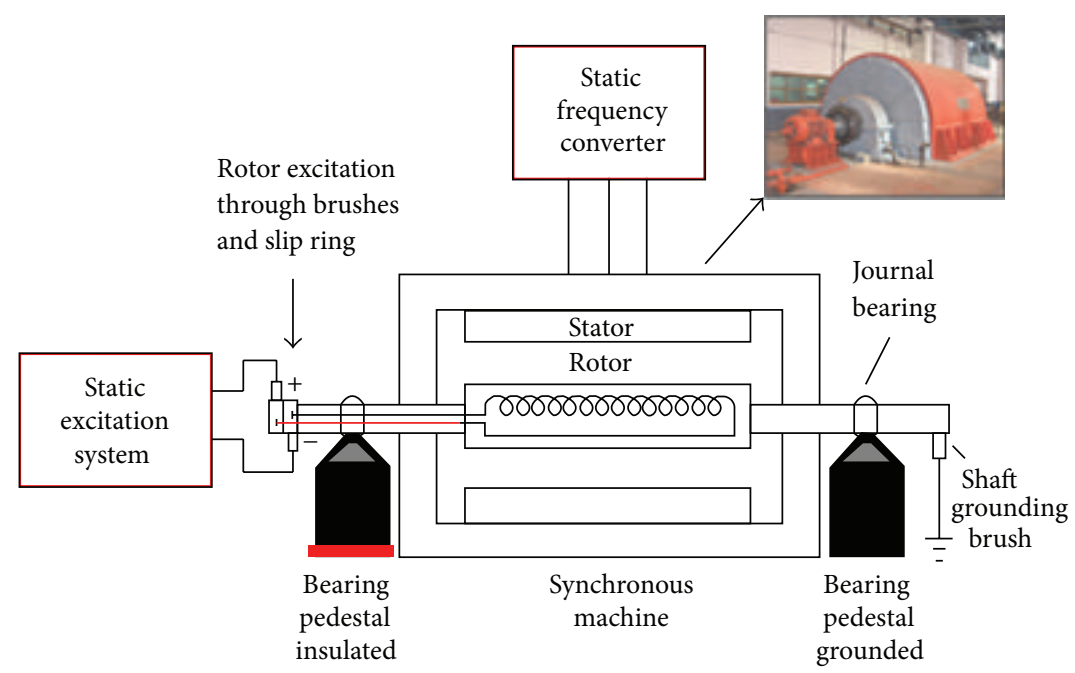

FIgURE 1: Short circuit alternator with the connected system.

to earth. This unwanted voltage is known as shaft voltage. It is a very old and common phenomenon in any electrical machine. Shaft voltage was noticed in the beginning of the 20th century by the engineers while studying different motor failure cases. Shaft voltage in those days was based only on sinusoidal power sources. It was noticed mainly due to unbalance in magnetic fluxes because of various reasons. Application of nonsinusoidal or static sources came into practice many years after the invention of semiconductor devices. With this some new types of shaft voltages appeared [9]. It is proven that shaft voltage under static power source is more predominant due to electrostatic phenomenon rather than pure sine wave operation [10]. Static excitation system has also added a new type of shaft voltage on the basic shaft voltages [11].

Bearing currents are the outcome of presence of shaft voltages. There are three major types of bearing currents: circulating current, $d v / d t$ current, and discharge current [1214]. Each of these currents flows under different conditions. Other than the mechanical reasons, majority of the premature bearing failures are due to the flow of these bearing currents. Common mode voltage (CMV) [15] is also responsible to flow current through machine bearings to ground. Many authors [16-18] presented different inverters topologies to eliminate CMV. Various filtering techniques (e.g., active, passive, or hybrid) are also proposed to safeguard the motor from the ill effects of CMV [19-21].

Most of the shaft voltage and bearing current problems and solutions related to work were carried out on induction motor $[22,23]$. This paper creates a different approach by taking a high power short circuit alternator for the study.

SES has great operation flexibilities compared to the other methods of excitation. It is also cheaper than the old conventional motor-generator set. Fast response characteristic, easy monitoring control, and troubleshooting are some other advantages of SES. In spite of several benefits, generation of shaft voltage is the major concern among the machines with static sources. The shaft voltage problem in the short circuit alternator has already been reported earlier [24-26].

This paper begins with the description of SES. Waveforms at various key points are recorded with the high speed recorder and stored for further analysis. A Simulink model has been prepared with the help of different parameters from converter bridge. The model is run and the results are compared with the actual waveforms recorded from the system. A discussion on the shaft voltage is brought out with these results.

\section{SES: Description}

SES converts line frequency AC to DC which further energises field winding in the rotor. Excitation level in a machine is needed to vary according to the different modes of the machine. This is only possible with a phase controlled rectifier. Now, to improve the power factor and to reduce the harmonic level of the system, a poly-pulse AC-DC power conversion [27] is required. To maintain this theory a 12-pulse converter configuration is adopted for SES in short circuit alternator. It is formed by a series combination of two 6pulse thyristor based silicon-controlled rectifier (SCR). Rotor current is very high value in alternator mode. To cope with this current two thyristors are put in parallel in each leg of the bridge. Detailed drawing is depicted in Figure 2.

The circuit begins with a specially designed converter transformer at the bridge input. It is a step down transformer with one primary and two secondary windings. Secondary windings are in star and delta fashion to get a $30^{\circ}$ phase shift between them. Rectified six-pulse outputs of each converter bridge are connected in series to form a 12-pulse output. This current is controlled by changing the thyristor gate pulses from the control cubicle. A dc circuit breaker does the switching action between SES and rotor circuit. SES panel is divided into two main parts (see Figure 3). One is power cubicle, consisting of thyristors and snubber circuits. The second part is 


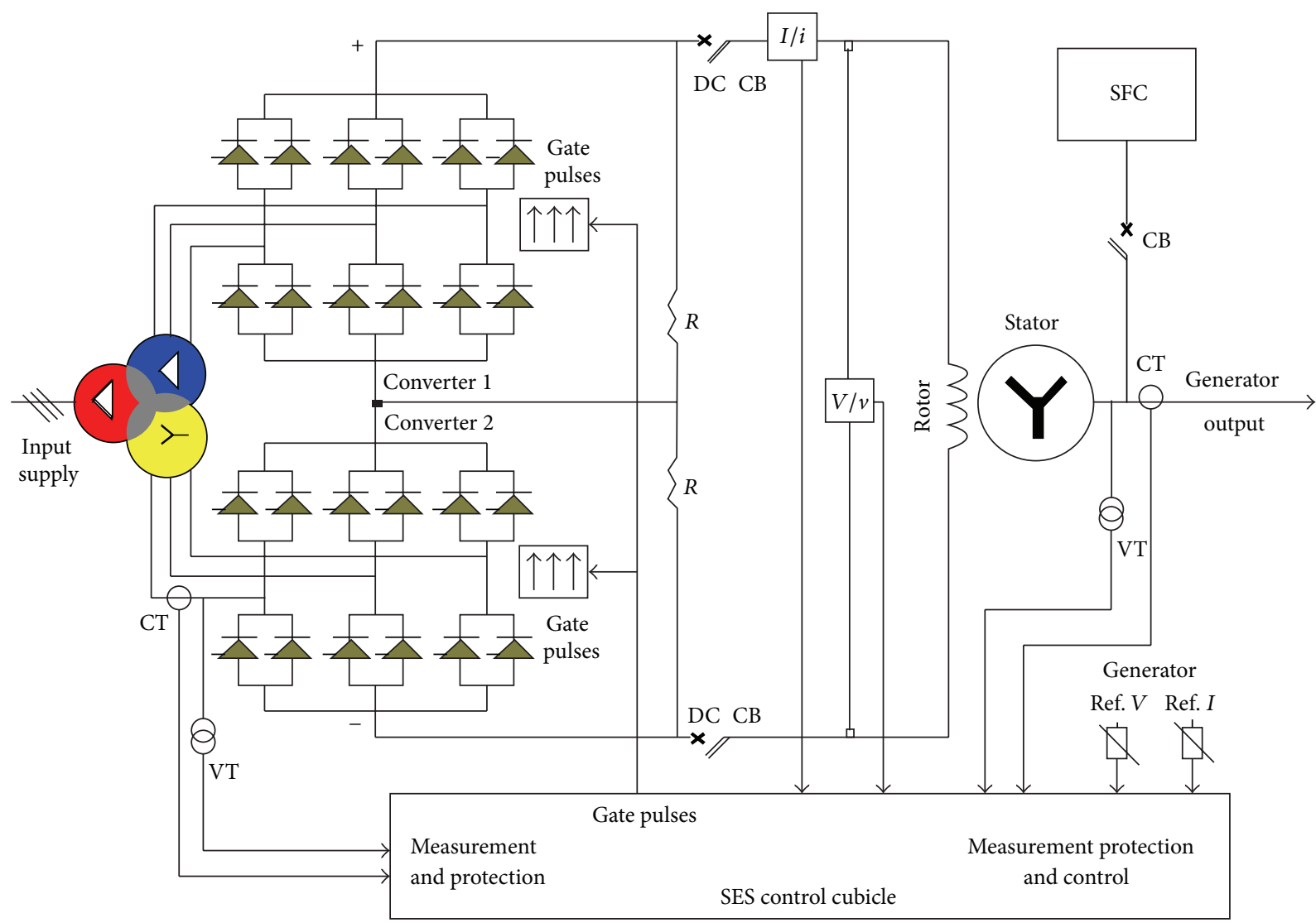

FiguRE 2: Circuit diagram of static excitation system.
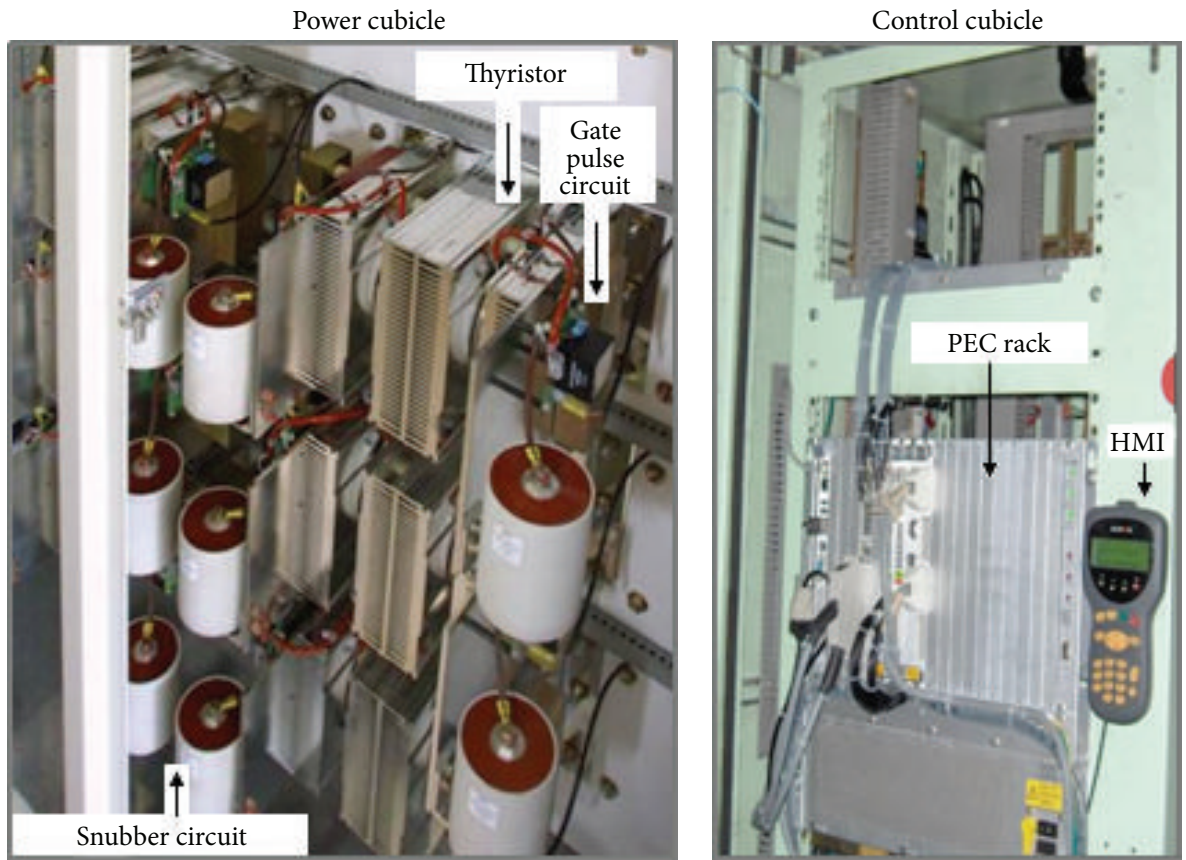

FIGURE 3: Static excitation system for 1500 MVA short circuit alternator. 


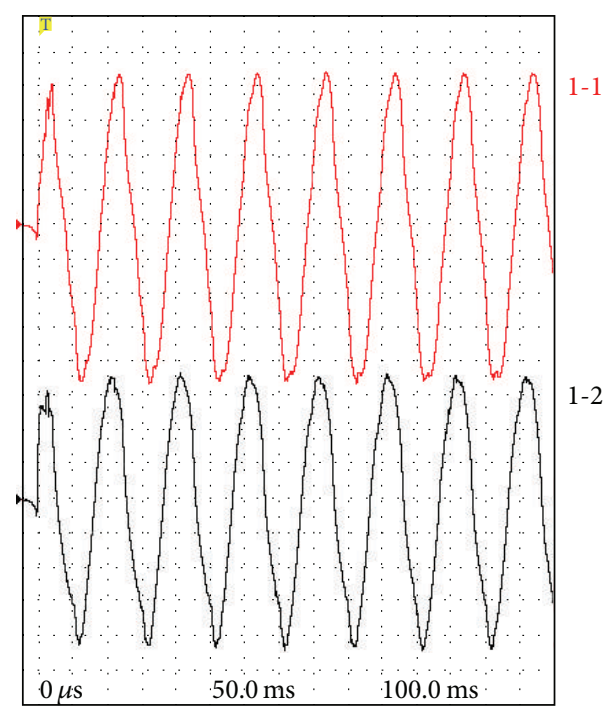

FIGURE 4: Converter input voltages from transformer (top: star winding 950 Vrms, bottom: delta winding 950 Vrms).

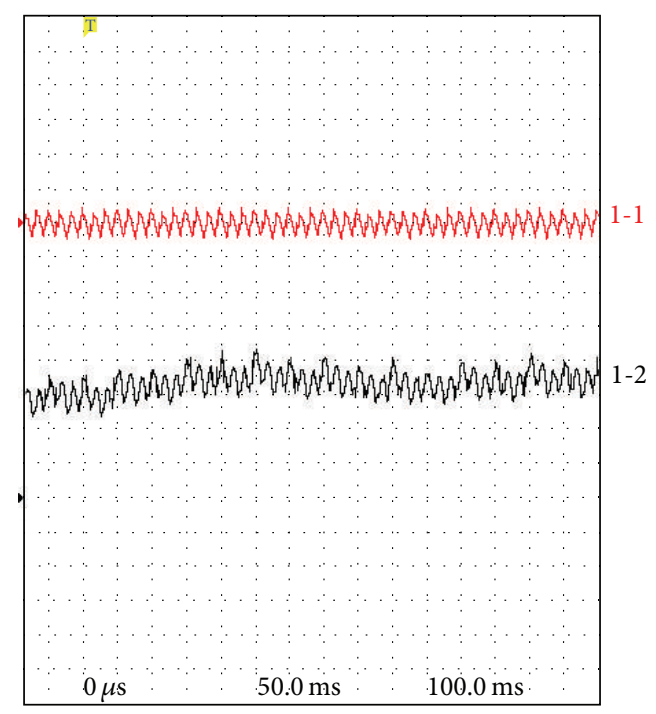

FIGURE 5: Rotor supply for a $3 \mathrm{kV}$ stator output (top: field voltage $30 \mathrm{~V}$, bottom: field current $400 \mathrm{~A}$ ).

the CPU with other electronic control circuitry and feedback loops. It is named as power electronic controller (PEC) and acts very fast in a $\mu$ sec range during short circuit test sequence [28]. A human machine interface (HMI) fitted on the controller visualises all faults and abnormality records in the SES.

\section{SES: Waveforms}

SES waveforms are measured at converter input and output and displayed in Figures 4, 5, and 6. Figure 4 depicts the star and delta input voltages of the converter bridge. A $30^{\circ}$ phase shift between the two voltages can be observed (see Figure 4). Converter output applied on the alternator field winding and current flowing through it are shown in Figure 5. This is for a $3 \mathrm{kV}$ alternator output (see Figure 6).

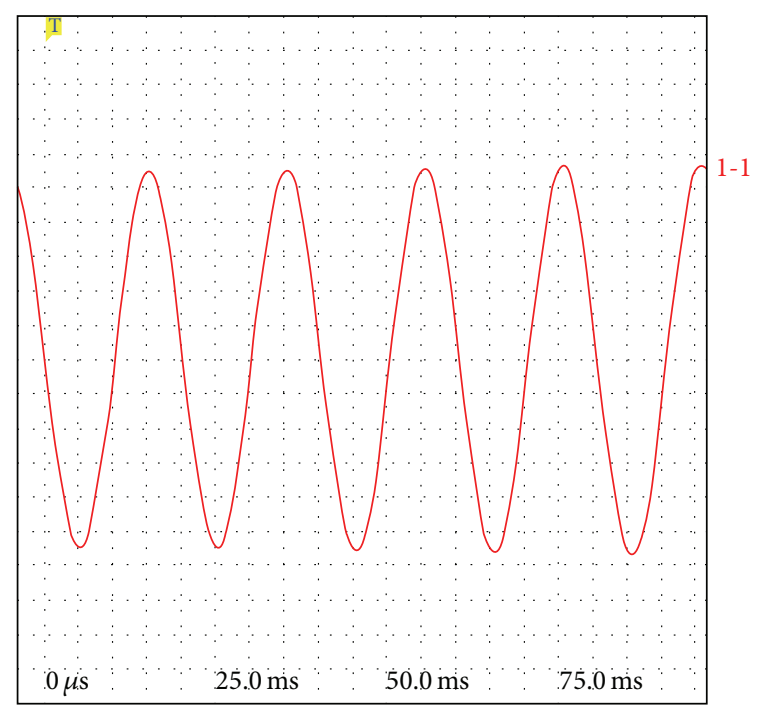

FIgURE 6: Generator output $3 \mathrm{kVrms}, 50 \mathrm{~Hz}$.

TABLE 1: SES model parameter values.

\begin{tabular}{lc}
\hline Parameter & Value \\
\hline Input source & $33 \mathrm{kV}, 3$ phases \\
Transformer nominal power & $5 \mathrm{MVA}$ \\
Transformer primary input & $33 \mathrm{kV}, 50 \mathrm{~Hz}$ \\
Transformer secondary output star winding & $950 \mathrm{~V}$ \\
Transformer secondary output delta winding & $950 \mathrm{~V}$ \\
Thyristor bridge & $3 \mathrm{arms}$ \\
Snubber resistance & $500 \Omega$ \\
Snubber capacitance & $0.1 \mu \mathrm{F}$ \\
Forward resistance & $1 \mathrm{~m} \Omega$ \\
Forward voltage & $0.8 \mathrm{~V}$ \\
Generator field resistance & $0.01 \Omega$ \\
Generator field inductance & $20 \mathrm{mH}$ \\
\hline
\end{tabular}

\section{SES: Modelling}

Modelling of SES is done to understand its intricacies in a simple manner. It has already been mentioned that SES is a combination of two thyristor bridges in series connection. The same has been modelled in Simulink [29] platform (see Figure 7) with one supply source, input transformer, two thyristor converters, pulse generators, and other circuitries. The model is formed with the variables listed in Table 1. All these parameters are taken from the actual converter.

\section{Simulation Results and Discussion on Shaft Voltage}

After running simulation the scope window displays different waveforms (see Figure 8). For better representation rotor voltage, rotor current, and reference current are plotted (see Figure 9) through MATLAB script file. The simulated traces 


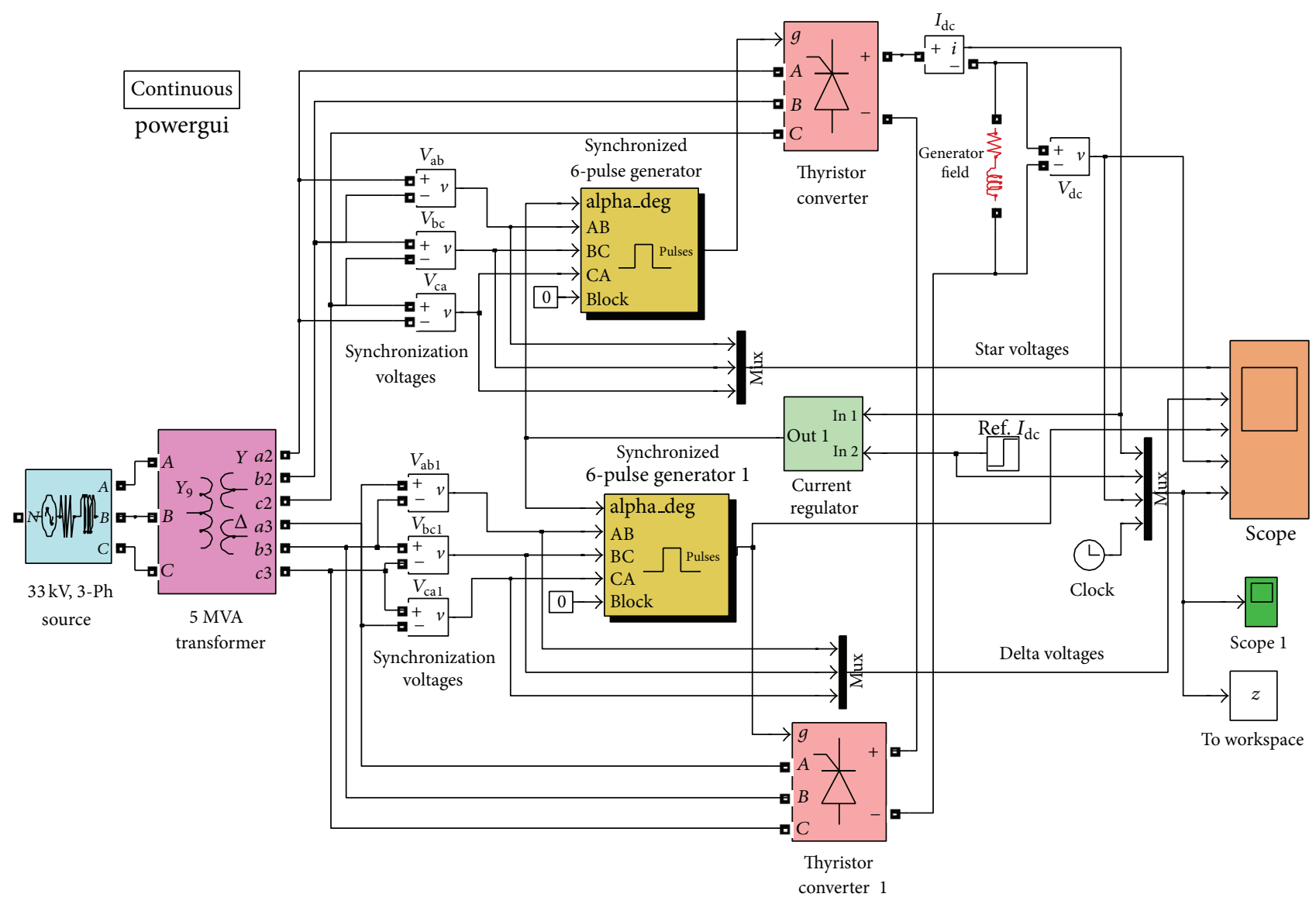

FIGURE 7: Simulink model of SES.

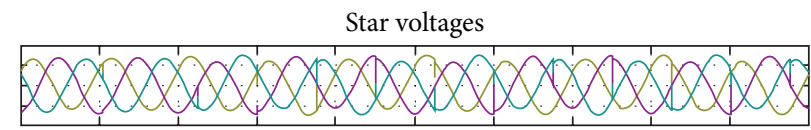

(a)

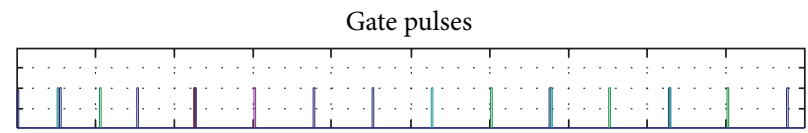

(c)

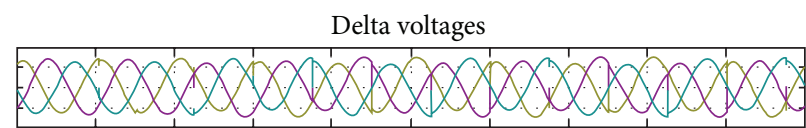

(b)

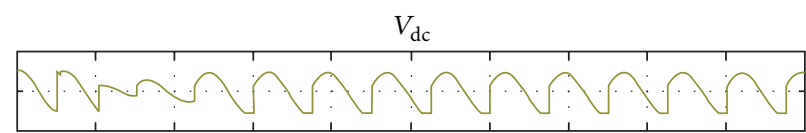

(d)

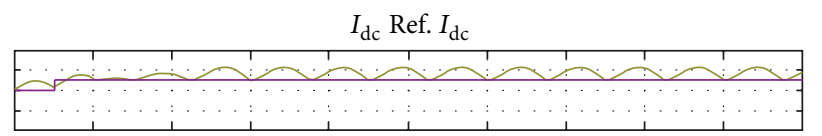

(e)

Figure 8: Scope view of simulation run (a) star voltage, (b) delta voltage, (c) gate pulses, (d) dc voltage, and (e) dc current and ref. dc current.

and actual waveforms from the measurements points of SES are compared which show similarities. Rotor voltage and current are pulsating in nature. It contains numbers of low and high order harmonics. This is confirmed by Fourier transform. Figure 10 shows the fast Fourier transform (FFT) analysis for actual rotor voltage whereas Figure 11 is the FFT for simulated waveform. Similarly FFT for rotor current waveforms are depicted in Figures 12 and 13.
Presence of harmonics and other high frequency signals causes the capacitive and inductive couplings in the complete alternator system. Winding insulation, air, and lubricating oil work as dielectric medium for forming the distributed capacitances in the machine. These capacitances (also called parasitic capacitances) form in stator to ground, stator to rotor, stator to shaft, rotor to shaft, bearing to ground, cable to ground, and also supply source to ground. Leakage current 


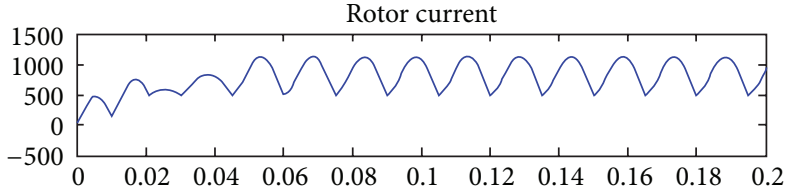

(a)

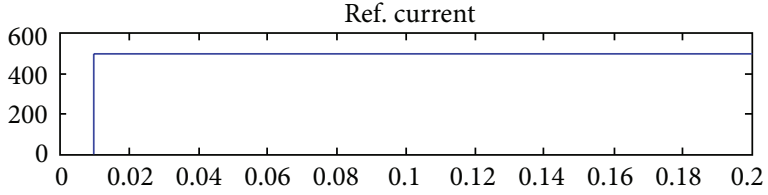

(b)

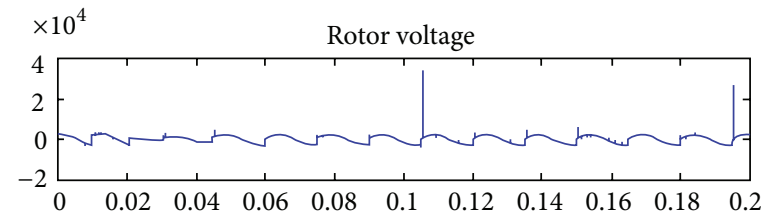

(c)

FIGURE 9: SES simulation results (a) rotor current (A), (b) reference current (A), and (c) rotor voltage (V).

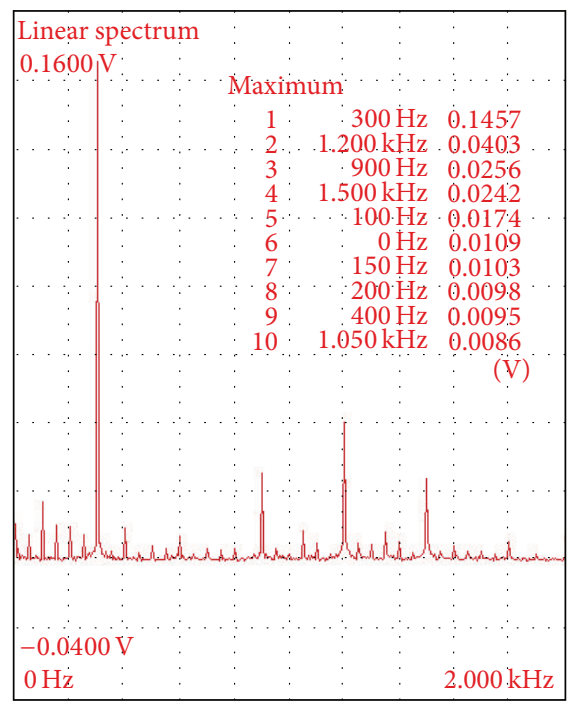

FIgURE 10: FFT for actual rotor voltage.

$\left(I_{c}=C \cdot d v / d t\right)$ flows all along the stator and rotor windings due to this parasitic capacitance $(C)$ and high $d v / d t$. This leakage current generates high frequency flux. Harmonics and other high frequency spikes in the stator and rotor power supply also generate high frequency flux. These cumulative fluxes link with winding, core, frame, shaft, and other metallic parts. In this way the inductive coupling is formed. Capacitive and inductive couplings together give an additive effect for the generation of shaft voltages for this long shaft machine.

As long as the shaft is insulated from ground at one end, then circulating current will not flow. In the presence of voltage, shaft acts like a charged capacitor with lubricating oil as a dielectric medium. Shaft is kept at ground potential with two grounding brushes. But during high speed rotation it is not possible to keep shaft at ground potential all the time. When the contact resistance of the grounding brushes is high (due to poor contact or contamination) the charged shaft discharges creating short high current impulses. Electrostatic discharges (see Figures 14 and 15) also happen between shaft and bearing when dielectric breakdown of lubricating oil

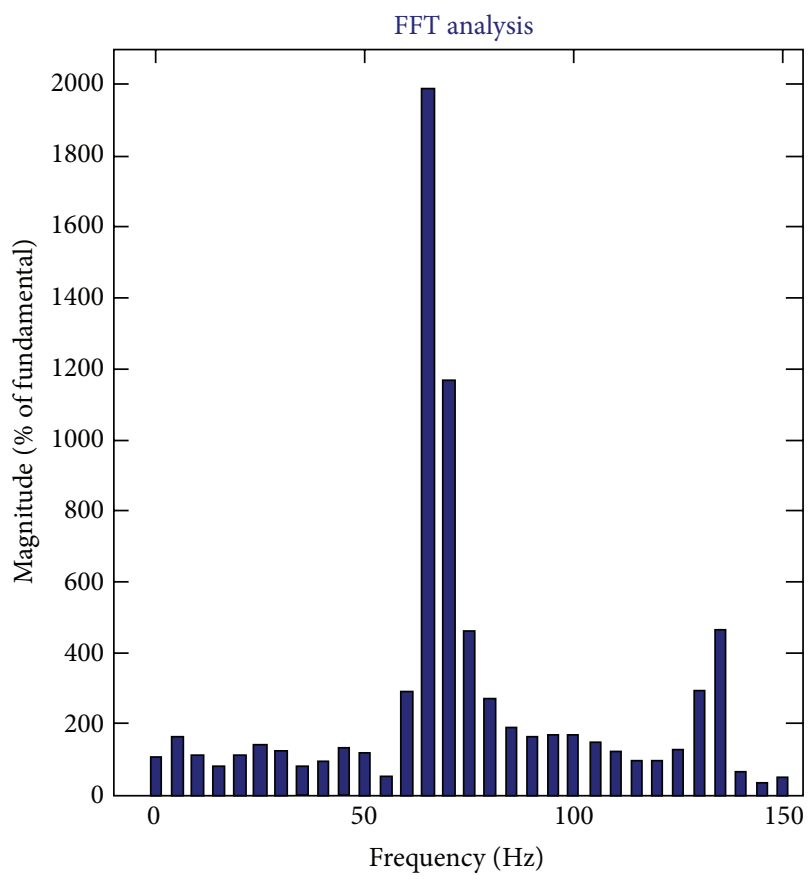

FIGURE 11: FFT for simulated rotor voltage.

film takes place due to close proximity or high voltage. The discharge current pulses contain high amount of energy. This energy is the prime source of bearing erosion and is commonly known as fluting or electric discharge machining (EDM) [30]. This EDM can damage bearing, shaft, and other nearby metal parts. As an example, pitting on a shaft due to shaft discharge is shown in Figure 16.

\section{Conclusion}

With the prime features, such as quick response, easy monitoring, control, and troubleshooting, SES has made the first choice of the designer for machine field excitation system. The SES discussed in this system is responsible for operating a single machine under different mode. Without any prime 


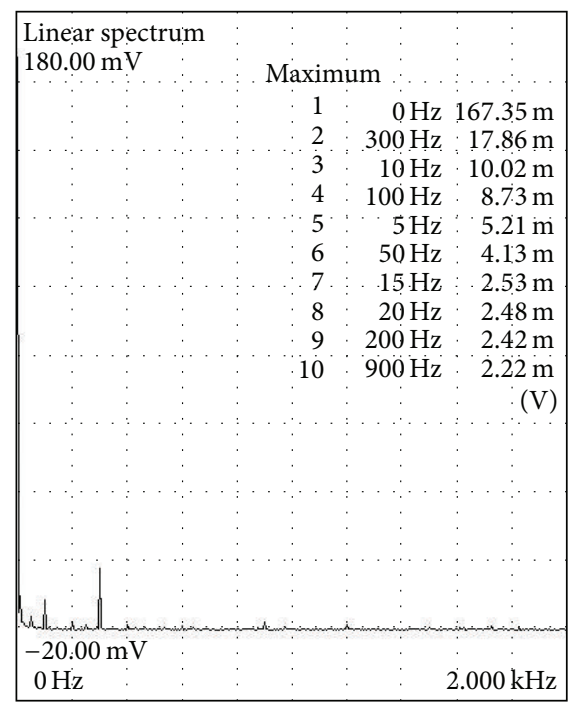

FIGURE 12: FFT for actual rotor current.

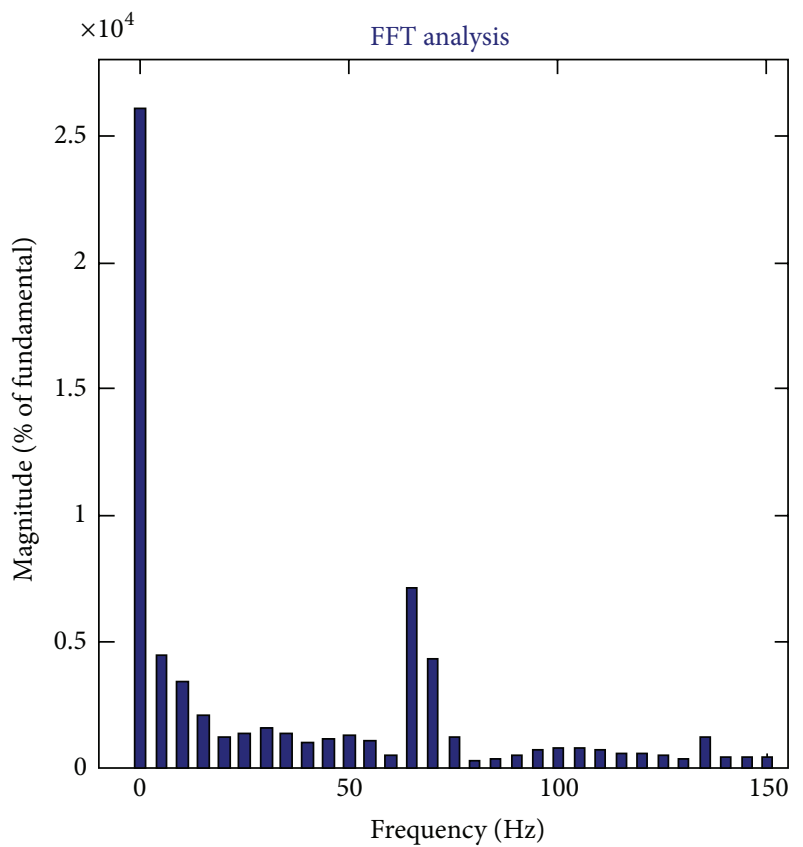

FIGURE 13: FFT for simulated rotor current.

mover this large machine can be started softly without much loading of the supply source. The machine can run as a motor or generator. The SES can also be used for braking or reversal operation of the machine. The SES applied in a short circuit alternator is analysed with the recorded waveforms. The same is modelled with the help of Simulink in MATLAB. Simulated waveforms are compared with the real ones found similar in nature.

In spite of several advantages the negative side of this technology is the generation of shaft voltage. Sparking on the grounding brushes is the evidence of presence of shaft voltages. Many reasons are behind this unwanted voltage, for example, capacitive coupling, inductive coupling, and

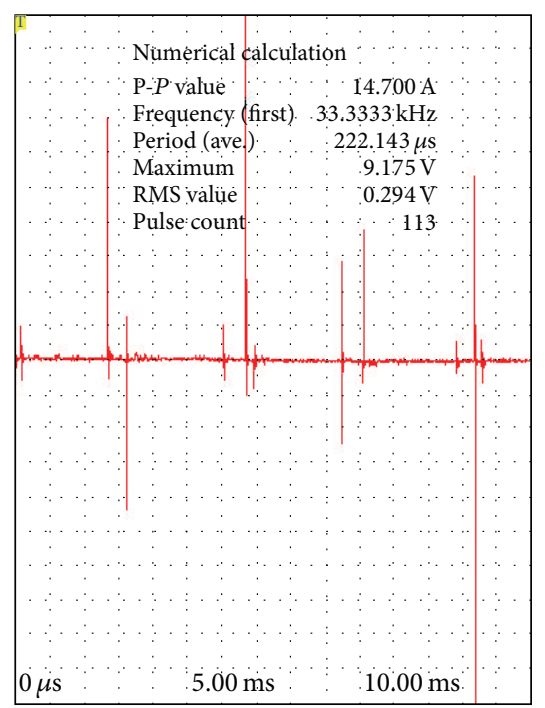

FIGURE 14: Recorded signals of EDM pulses.

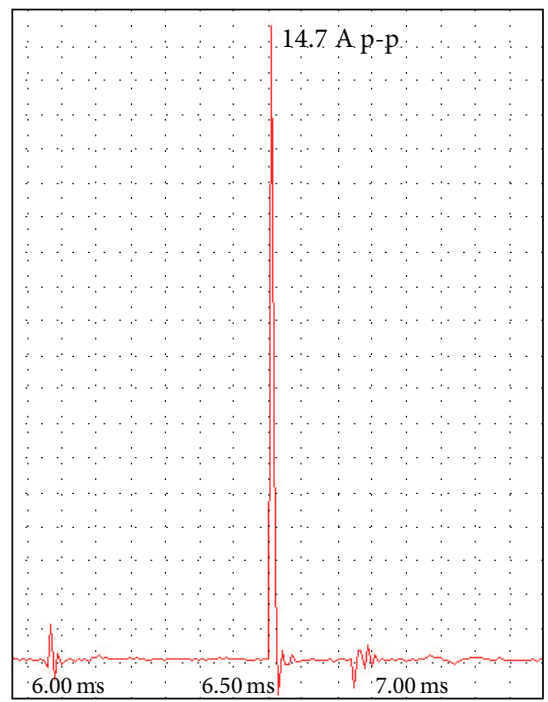

FIGURE 15: Close look on a single EDM pulse.

common mode voltage. Thyristors switching in the converter bridge and high level of harmonics in current and voltage cause capacitive and inductive couplings. This was proven by the FFT analysis on current and voltage waveforms. Both the simulated and actual measurements show that the waveforms contain high percentage of harmonics.

Among the various types of bearing currents discharge mode current or EDM is the most harmful causing erosion on the shaft and bearings. Life of machine is reduced by this effect. Large machine requires huge investments on shaft repair and bearing replacement. To arrest the premature bearing failure further study in this field is needed to eliminate the shaft voltage. 


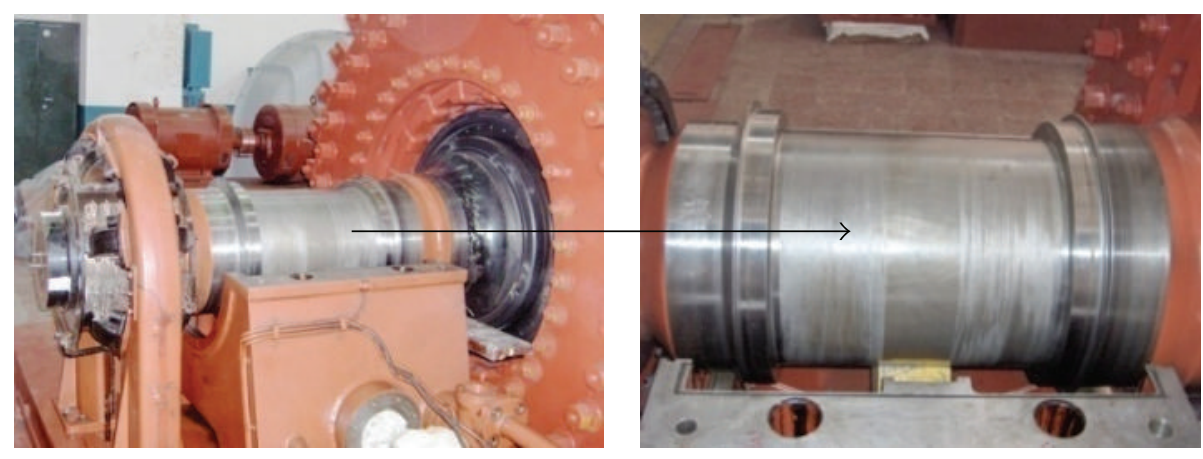

FIGURE 16: Pitting on journal shaft due to EDM.

\section{Conflict of Interests}

The authors declare that there is no conflict of interests regarding the publication of this paper.

\section{Acknowledgment}

Authors are thankful to the management of Central Power Research Institute, India, for supporting this work.

\section{References}

[1] L. J. Lane, D. F. Rogers, and P. A. Vance, "Design and tests of a static excitation system for industrial and utility steam turbinegenerators," AIEE, vol. 80, no. 3, pp. 1077-1085, 1962.

[2] R. C. Schaefer, "Applying static excitation systems," IEEE Industry Applications Magazine, vol. 4, no. 6, pp. 41-49, 1998.

[3] Y.-Z. Zhang, "Study of process of starting pumped storage machines by static frequency converter with field current controlled," in Proceedings of the 2nd International Conference on Signal Processing Systems (ICSPS '10), pp. V1224-V1227, July 2010.

[4] R. B. Fisher, "Introduction of static frequency converters on SEPTA's 25-Hz commuter rail system," in 1990 ASME/IEEE Joint Railroad Conference, pp. 149-155, April 1990.

[5] S.-H. Park, S.-H. Hwang, J.-M. Kim, H.-S. Ryu, and J.-H. Lee, “A starting-up control algorithm of large synchronous generation motor for gas turbosets," in Proceedings of the IEEE International Symposium on Industrial Electronics (ISIE '08), pp. 502-508, Cambridge, UK, June 2008.

[6] H. Taguchi, S. Tamai, Y. Hosokawa, and A. Ando, "APS control method for gas turbine startup by SFC," in Proceedings of the International Power Electronics Conference, pp. 264-269, IEEE, 2010.

[7] A. K. Datta, M. Dubey, N. R. Mondal, and B. V. Raghavaiah, "Motor-less operation of short circuit generator-a CPRI perspective," in Proceedings of the International Conference on Electrical Power and Energy Systems (ICEPES '10), pp. 439-445, MANIT, Bhopal, India, August 2010.

[8] A. K. Datta, M. A. Ansari, N. R. Mondal, and B. V. Raghavaiah, "A novel use of power electronics: prime mover-less alternator with static drive \& excitation system," International Journal of Electronics \& Communication Technology, vol. 3, no. 1, pp. 472475, 2012.

[9] A. K. Datta, M. Dubey, and S. Jain, "Study of shaft voltage \& bearing currents in electrical machines," in Proceedings of the IEEE Students' Conference on Electrical, Electronics and Computer Science (SCEECS '12), pp. 1-4, Bhopal, India, March 2012.

[10] J. M. Erdman, R. J. Kerkman, D. W. Schlegel, and G. L. Skibinski, "Effect of PWM inverters on AC motor bearing currents and shaft voltages," IEEE Transactions on Industry Applications, vol. 32, no. 2, pp. 250-259, 1996.

[11] C. Ammann, K. Reichert, R. Joho, and Z. Posedel, "Shaft voltages in generators with static excitation systems-problems and solution," IEEE Transactions on Energy Conversion, vol. 3, no. 2, pp. 409-419, 1988.

[12] S. Chen and T. A. Lipo, "Circulating type motor bearing current in inverter drives," IEEE Industry Applications Magazine, vol. 4, no. 1, pp. 32-38, 1998.

[13] A. Muetze and A. Binder, "Calculation of circulating bearing currents in machines of inverter-based drive systems," IEEE Transactions on Industrial Electronics, vol. 54, no. 2, pp. 932-938, 2007.

[14] A. Muetze, "On a new type of inverter-induced bearing current in large drives with one journal bearing," IEEE Transactions on Industry Applications, vol. 46, no. 1, pp. 240-248, 2010.

[15] H.-S. Ryu, B. Kim, J. Lee, and I. Lim, "A study of synchronous motor drive using static frequency converter," in Proceedings of the 12th International Power Electronics and Motion Control Conference (EPE-PEMC '06), pp. 1496-1499, IEEE, September 2006.

[16] N. Zhu, D. Xu, B. Wu, N. R. Zargari, M. Kazerani, and F. Liu, "Common-mode voltage reduction methods for current-source converters in medium-voltage drives," IEEE Transactions on Power Electronics, vol. 28, no. 2, pp. 995-1006, 2013.

[17] R. S. Kanchan, P. N. Tekwani, and K. Gopakumar, "Three-level inverter scheme with common mode voltage elimination and $\mathrm{dc}$ link capacitor voltage balancing for an open-end winding induction motor drive," IEEE Transactions on Power Electronics, vol. 21, no. 6, pp. 1676-1683, 2006.

[18] M. R. Baiju, K. K. Mohapatra, R. S. Kanchan, and K. Gopakumar, "A dual two-level inverter scheme with common mode voltage elimination for an induction motor drive," IEEE Transactions on Power Electronics, vol. 19, no. 3, pp. 794-805, 2004.

[19] K. K. Yuen, H. S. Chung, and V. S. Cheung, "An active lowloss motor terminal filter for overvoltage suppression and common-mode current reduction," IEEE Transactions on Power Electronics, vol. 27, no. 7, pp. 3158-3172, 2012.

[20] Z. Zhao, Y. Zhong, H. Gao, L. Yuan, and T. Lu, "Hybrid selective harmonic elimination PWM for common-mode voltage reduction in three-level neutral-point-clamped inverters for variable 
speed induction drives," IEEE Transactions on Power Electronics, vol. 27, no. 3, pp. 1152-1158, 2012.

[21] H. Akagi and K. Isozaki, "A hybrid active filter for a three-phase 12-pulse diode rectifier used as the front end of a mediumvoltage motor drive," IEEE Transactions on Power Electronics, vol. 27, no. 1, pp. 69-77, 2012.

[22] F. Wang, "Motor shaft voltages and bearing currents and their reduction in multilevel medium-voltage PWM voltage-sourceinverter drive applications," IEEE Transactions on Industry Applications, vol. 36, no. 5, pp. 1336-1341, 2000.

[23] H. Akagi and T. Doumoto, "An approach to eliminating highfrequency shaft voltage and ground leakage current from an inverter-driven motor," IEEE Transactions on Industry Applications, vol. 40, no. 4, pp. 1162-1169, 2004.

[24] A. K. Datta, M. Dubey, and S. Jain, "Effect of static power supply in alternator used for short-circuit testing-observation of shaft voltage," IEEE Transactions on Power Electronics, 2014.

[25] A. K. Datta, M. Dubey, and S. Jain, "Investigation of bearing currents in dual mode operation of synchronous machine with static excitation system," Electrical and Electronics Engineering, vol. 2, no. 4, pp. 45-53, 2013.

[26] A. K. Datta, M. Dubey, and S. Jain, "Study of shaft voltage on short circuit alternator with static frequency converter," International Journal of Electrical, Electronic Science and Engineering, vol. 7, no. 11, pp. 692-698, 2013.

[27] T.-J. Liang, J.-F. Chen, C.-L. Chu, and K.-J. Chen, "Analysis of 12 pulse phase control AC/DC converter," in Proceedings of the $3 \mathrm{rd}$ IEEE International Conference on Power Electronics and Drive Systems (PEDS '99), pp. 779-783, Hong Kong, July 1999.

[28] A. K. Datta, G. Venkateswarlu, M. A. Ansari, and N. R. Mondal, "Excitation control during short circuit test sequence of 1500 MVA short circuit generator," in Proceedings of the International Conference on Advances in Computer, Electronics \& Electrical Engineering (ICACEEE '12), pp. 207-211, Mumbai, India, March 2012.

[29] The MathWorksTM, Inc., USA, Release 2008a (R2008a).

[30] S. Bell, T. J. Cookson, S. A. Cope et al., "Experience with variable-frequency drives and motor bearing reliability," IEEE Transactions on Industry Applications, vol. 37, no. 5, pp. 14381446, 2001. 

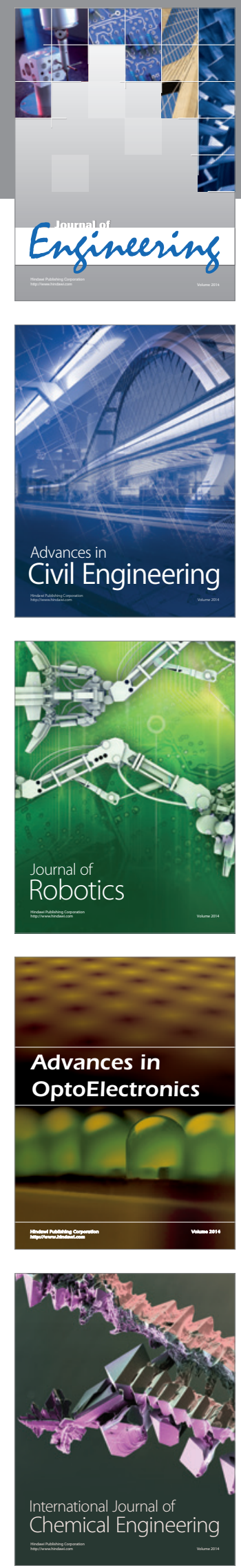

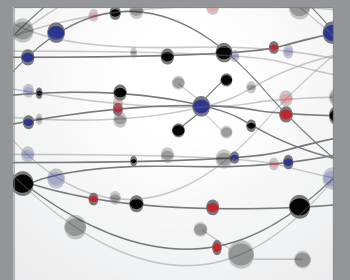

The Scientific World Journal
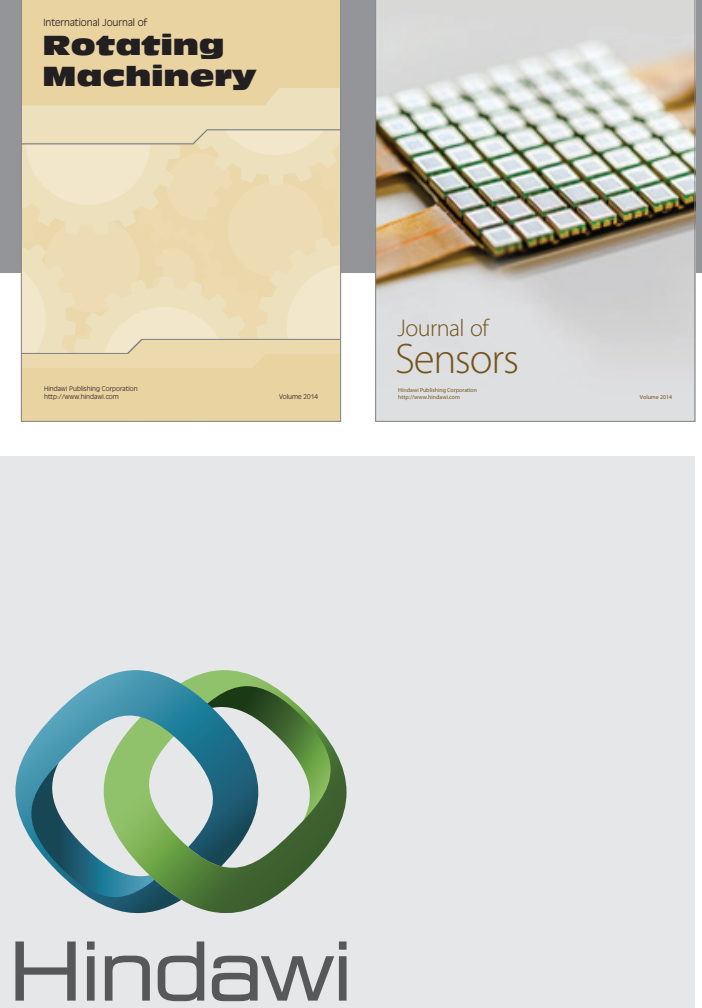

Submit your manuscripts at http://www.hindawi.com
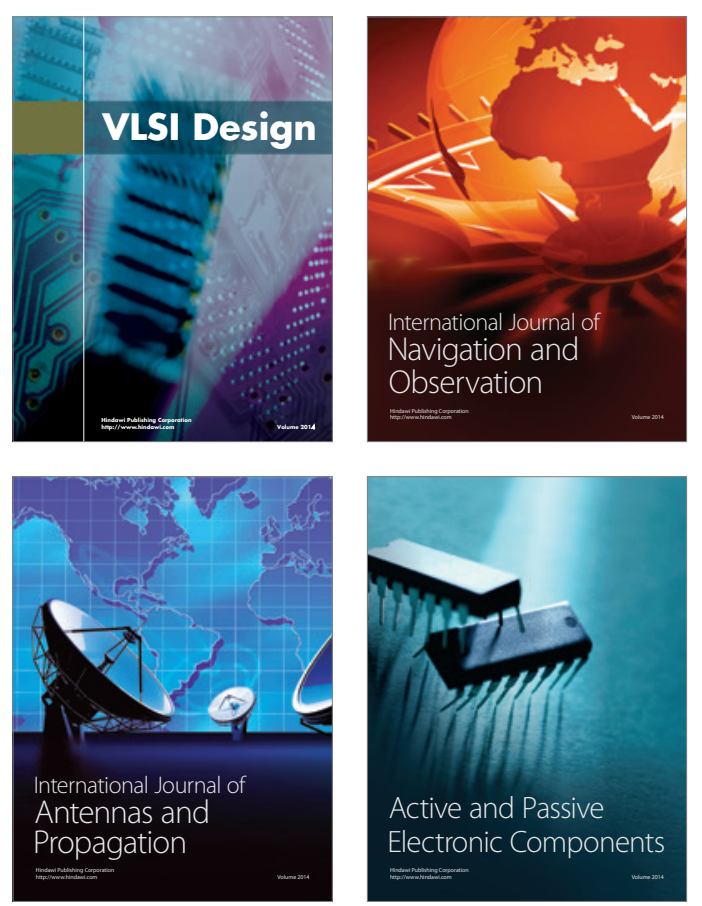
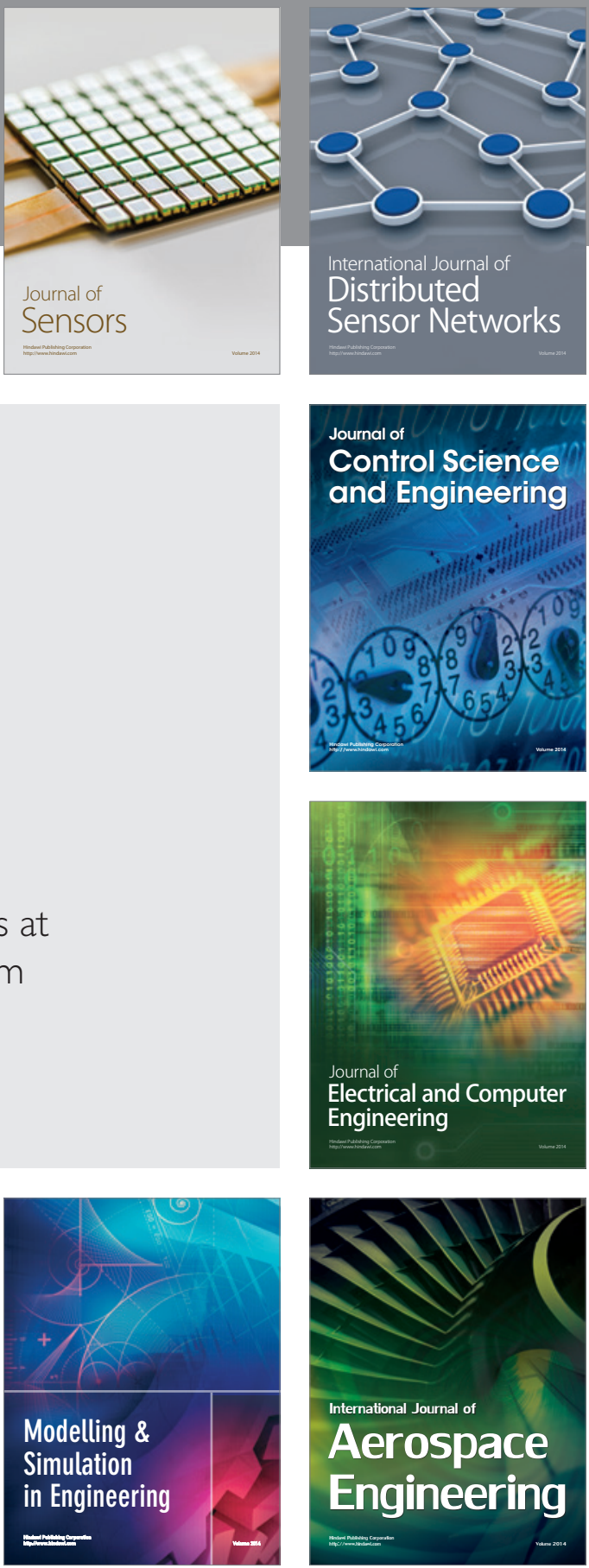

Journal of

Control Science

and Engineering
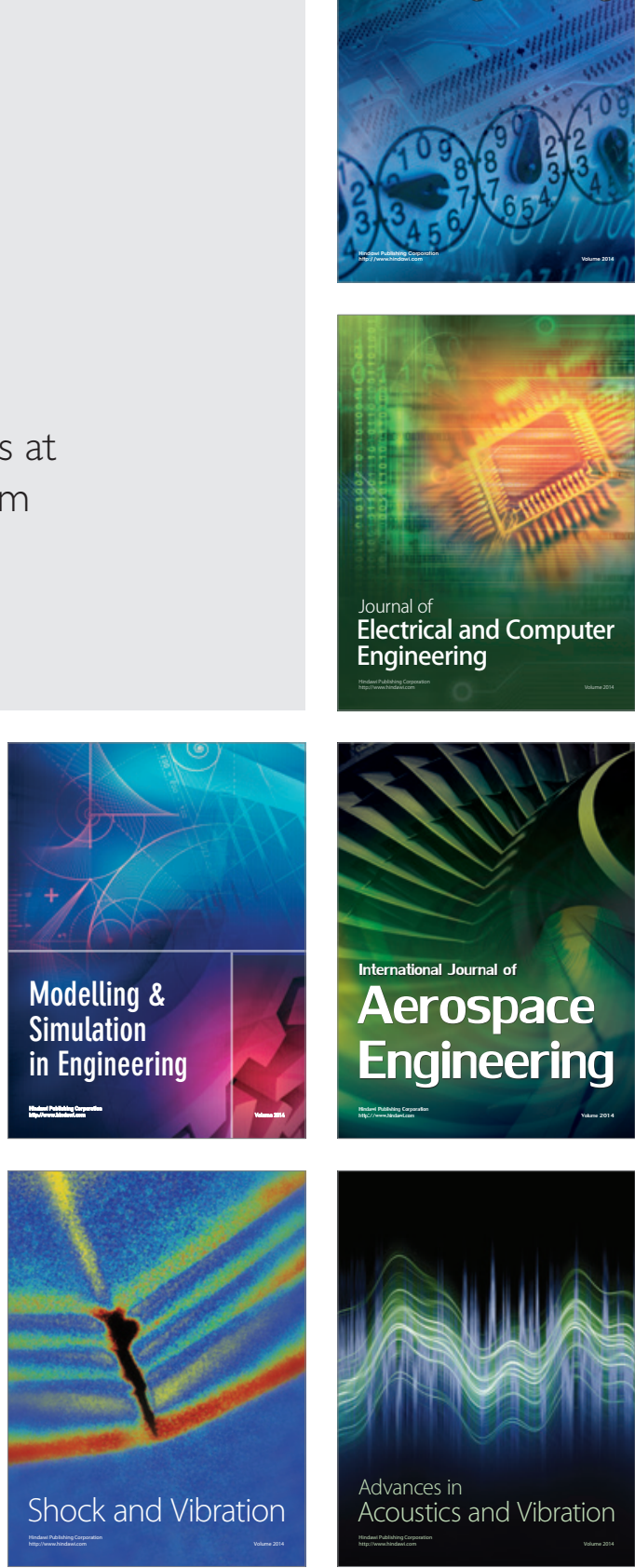